4. In the scheme the county system has been adopted, because it is the system upon which the Territorial Force is organised, and which the British Red Cross Society has adopted as the basis of its constitution.

5. The County Association therefore is charged with the responsiility of the organisation of voluntary aid in the country.

6. Fach County Association should through the medium of the local branches of the British Red Cross Society form " voluntary aid detachments," with an establishment which is laid down in the scheme; also each county group of voluntary ald detachments (and there need be no limit to the number of such detachments), should he under the command of a County Director, and each detachment should be capable of being used either as a clearing hospital, or as a rest station or as an ambulance train personnel, as the circumstances of the moment may demand in the time of war.

7. Hach voluntary aid detachment should therefore be trained in such manner as will enable it to perform any one of these functions.

8. The training and equipment of voluntary aid detachments will be carried out in whatever way the British Red Cross Society may think it; but they should be so arranged as to enable the detachments to make use of local resources for improvising accommodation and transport of wounded, and for providing for their temporary care and treatment until they reach the general hospitals. Men's detachments would therefore be specially trained in transport of wounded, and women's detachments in the preparation of food and in nursing duties

The personnel recommended for each Voluntary Aid Detachment is as follows:-A. Men's Division (British Red Cross Society): 1 commandant and 1 assistant-commandant (if possible these are to be officers with military medical training); 2 medical officers ; 1 quartermaster and 1 assistantquartermaster ; 2 pharmacists and 2 assistant-pharmacists ; 4 under officers and 48 men. B. Women's Division : 1 commandant and 1 assistant-commandant (these being medical officers); 1 quartermaster and 1 assistant-quartermaster ; 2 lady superintendents and 20 women, of whom 2 shall be fully trained nurses. This establishment allows of the divison of the whole detachment into two completely organised halves.

9. In order to obtain some uniformity in the standard of efficiency of voluntary aid detachments there will be annual or other inspections by military authorities, and a return of the members of each detachment will be submitted through the county associations to general officers commanding-in-chief periodically by each county director of voluntary aid detachments.

10. In time of war the evacuation of sick and wounded of the Territorial Forces will be under the direction of officers of the Royal Army Medical Corps or other officers appointed for the purpose, and voluntary aid detachments will be placed at their disposal and under their orders according to requirements.

11. If county associations fail to obtain an organisation of voluntary 11. If county assoclations lall to obtain an organisation of voluntar ambulances and general hospitals they must report the facts to ger officers commanding-in-chief.

12 12. As regards general hospitals, county associations should either themselves or through the British Red Cross Society proceed to select the necessary buildings in consultation with administrative medical of cers, omeers con sanitary officers of their territorial division ; and plans should be drawn up showing
how the buildings will be arranged for hospital purposes; the organising

13. Scholng bensulted regarding the

13. Schedules of equipment for general hospitals are drawn up in the scheme as a guide. County associations should delegate to the British Red Cross Society the duty of providing the equipment and should satisfy themselves that it will be ready on mobilisation

14. Supplementary personnel required for general hospitals should be obtained from voluntary aid detachments which will be allotted on mobilisation for this purpose only.

15. Wounded may accumulate in excess of the number of beds vacant in the general hospitals. The formation of convalescent homes and depôts and provision for expansion of the general hospitals must therefore be contemplated. County associations should be responsible for taking the initiative in asking the British Red Cross Society to submit schemes in time of peace for forming convalescent homes and auxiliary hospitals.

Full details of the scheme follow this outline, and three appendices describe (1) the organisation of the medical service of the Army ; (2) the organisation and resources of the Red Cross Society of Japan (a report by LieutenantColonel W. G. Macpherson, O.M.G., R.A.M.C.) ; and (3) the detailed equipment of military hospitals (comprising schedules of all furniture, utensils, medicines, and stores).

\section{Royal Navy Medical Service.}

The undermentioned Surgeons have been promoted to the rank of Staff-Surgeon in His Majesty's Fleet:-Thomas Brown Shaw, Alfred Thomas Gailleton, George Sandys Davidge, and Percival Thomas Nicholls (dated August 10th, 1909).

The following appointments are notified :-Fleet-Surgeons : F. W. Parker to Portland Hospital, and P. E. Maitland to the Albinn, on recommissioning. Staff-Surgeon: J. O'Hea to the Victory, additional, for disposal. Surgeons : L. C. Rowan-Robinson to the Drake; S. H. Vickery to the Impregnable; and W. Mearns to the Actacon.

Royal Army Medical Corps.

Lieutenant-Colonel R. J. S. Simpson, C.M.G., has been appointed to the Kastern Command for duty. LieutenantColonel A. T. I. Lilly and Major J. Thomson have been instructed to prepare for embarkation for India.

INDIAN MEDICAL SERVICE.

The promotion of Major Asher Leventon is antedated to Jan. 29th, 1907. The promotion of Major Jasper Maxwell Woolley is antedated to July 29th, 1908.

The King has approved of the following promotions:ieutenants to be Captains: Arthur Falconer Hayden (provisionally) (dated Sept. 1st, 1908) ; Percy Strickland Mill (provisionally) and Frank Phillips Wernicke (dated Feb. 1st 1909); and Charles Richard O'Brien, Norman Haliburton Hume, Greer Edmund Malcolmson, and Duncan Macdonald Cochrane Church (dated March 1st, 1909).

Major F. D. Browne has been appointed to the substantive medical charge of the 112th Infantry, Kohat; and Captain A. S. M. Peebles is appointed to the substantive medical charge of the 18th Lancers, vice Captain R. F. Baird.

ROYAL VICTORIAN ORDER.

The King has appointed Fleet-Surgeon Cyril James Mansfield, R.N., H.M.S. Indomitable, to be a Member of the Fourth Class of the Royal Victorian Order.

DeAths IN THE SERVICES.

Brigade Surgeon-Lieutenant-Colonel Edwin James Fairland, A.M.S. (retired), on August 6th, at Bournemonth, aged 65. He entered the service in 1867 as assistant-surgeon was promoted surgeon in 1873, surgeon-major in 1879 surgeon-lieutenant-colonel in 1887, and brigade surgeon lieutenant-colonel in 1893. He served in the Abyssinian campaign from November, 1867, to July, 1868 (medal). $\mathrm{He}$ retired in 1897.

THE Territorial ARMY iN WAR.

In an interesting article on "The Health of the Territorial Army in War," in the Broad Arron of August 14th, Lieutenant-Colonel W. Hill Climo, A.M.S. (retired), said that it is an unjustifiable assumption " that, as the Territorial Army will not be serving outside the United Kingdom, it will not be exposed to conditions inimical to health either in regard to its endurance or to environment and climate. Some such optimistic opinions were held about the Boer War, and we know with what disastrous results, though probably the climate of South Africa is the most favourable in the world for the conduct of a campaign, and though no army ever before was so lavishly provided with food and other supplies. An army, organised as the Territorial Army is, if mobilised for service in the Garden of Eden, would, under service conditions, be liable to dysentery and enteric fever. In England it would be impossible to bring 10,000 troops together free from the seeds of enteric fever, which under the stress of war would become epidemic. The best medical service in the world could not prevent its occurrence with unseasoned and immature troops. Voluntary service armies are notoriously the most unhealthy, and the Anglo-Saxon race is perhaps the most susceptible to these epidemic diseases, the brunt of which falls on the intestinal tract."

\section{Contespondente.}

\section{"Audi alteram partem." \\ THE DANGERS OF CARBON TETRA- CHLORIDE \\ To the Editor of THE LANCET.}

SrR,-I have read with much interest the article published in your issue of August 7th on the toxicity of carbon tetrachloride. Three cases in which ill effects have followed the use of a dry shampoo have recently come to my notice. In the first case, a girl, aged 22 years, became, according to her own statement, "completely unconscious" whilst her hair was being treated with a patent non-inflammable dry shampoo. Under the same treatment at the same hairdresser's a second lady, aged 26 years, became "deafer and deafer" until she was obliged to ask the operator to desist, fearing that she was going to faint. At another establishment a lady, aged 40 years, became so faint during the application of a dry 
shampoo that the process had to be stopped. All the windows in the room were thrown wide open, and at the end of half an hour the lady had sufficiently recovered to have her hair hastily dressed. Still feeling very faint and shaken, she was then driven straight to her home in a cab. These three cases occurred before the recent fatal case, and I have hesitated to publish them because although the histories came to me at first hand they were not given me in my professional capacity and were not scientifically investigated. The patients were in good health and almost certainly free from cardiac weakness.

I am astonished to learn that in spite of the recent fatality the use of this shampoo continues unchecked, the public being apparently lulled into a sense of security by the medical evidence, which stated that the lady who died suffered from heart disease. The hairdressers justify themselves by stating that although untoward symptoms occur amongst their customers the operators have never been known to have been affected. Their immunity is fully explained by the weight of the vapour of tetrachloride of carbon, which, according to Dr. Veley, is five times that of air. Unless my experience has been exceptional, there should be abundant clinical evidence in support of the views as to the dangers of tetrachloride of carbon which Dr. A. Waller and Dr. Veley base on laboratory experiment, and the use by hairdressers of shampoos containing so poisonous a substance should certainly be prohibited.

August 16th, 1909.

I am, Sir, yours faithfully,

J. E. Sandilands, M.D. Camb.

\section{THE NATURE OF ANGINA PECTORIS.}

\author{
To the Editor of THE LANCET.
}

SIR,-May I trespass on your space to urge once more the desirability of the abolition of the terms "false" angina pectoris, "pseudo" angina pectoris, and the like. In an article on angina pectoris which I contributed to THE LANCE'T in $1903,{ }^{1}$ I suggested that the name " angina cordis " might be applied to these and allied forms of cardiac perturbation. The term angina cordis, moreover, expresses more or less exactly the condition of the heart in these attacks and it can be suitably qualified in accordance with its mode of origin, as, for instance, angina cordis vaso-motoria, angina cordis toxicata, \&c. The adoption of this nomenclature would not only get rid of the misnomer and consequent nosological confusion involved in the use of the term "false" angina pectoris, \&c., but would also promote much greater precision in the recognition and description of several hitherto illdefined forms of anginal attack.

Might I also briefly comment on Sir T. Clifford Allbutt's position in respect to the causation of angina pectoris. As Sir R. Douglas Powell points out, it is hardly possible that aortic stretching can be the only cause of angina pectoris, nor, in $\mathrm{my}$ opinion, is it adequate to explain all the symptoms of the anginal attack. Furthermore, the large majority of the conditions that unquestionably give rise to aortic stress are not associated with anginal symptoms; and, on the other hand, true anginal attacks are not very uncommon, in my limited experience, without any evidence, either clinical or pathological, of aortic stretching.

I have urged the importance of the localised patchy distribution of the degenerative changes that may be found in the cardiac wall in cases of angina pectoris, since in the distension and stretching of these diseased areas during the cardiac systole I find an explanation of the phenomena of the anginal syndrome. For a full exposition of this hypothesis I must, out of consideration for your space, refer your readers to my article, but $I$ should like to point out that a satisfactory explanation of the pathogenesis of angina pectoris must account not only for the dolor pectoris but also for the angor animi.

London, W., August 14th, 1909.

I am, Sir, yours faithfully,

E. H. COLBECK.

To the Editor of THE LANCET.

SIR,-The few remarks which I propose to make on this important question are the result of $m y$ clinical experience of a very large number of cases of heart disease. I find that true angina pectoris major (I confine $m y$ attention to this) is

1 Angina Pectoris, a Criticism and a Hypothesis, Tre LAYCET, March 21st, 1903, p. 793 . an exceedingly rare condition amongst the poorer classes, and during the last 12 years, out of over 50,000 hospital cases of all varieties of disease, I have only met with three cases of angina pectoris ; on the other hand, amongst the well-to-do classes of society one meets with it more frequently, and especially in those males afflicted with gout. The hypothesis which I venture to put before you is, that true "angina pectoris is due to spasm or cramp of the heart muscle, which comes on suddenly after exertion as a rule, and passes off as it came."

I cannot here discuss the various theories which have been advanced by great authorities as to the cause of the symptoms which are so distressing and often fatal, but I will confine my remarks to one or two points. It has been said that angina pectoris is due to sudden dilatation of the auricles or ventricles, either in association with valvular disease or often severe heart strain. My clinical and post-mortem experience does not support that view. One frequently sees athletes after a severe and punishing race like a quarter mile, or during a football match, become "winded." The heart has become over-distended and they suffer from acute dyspnœa, but there is no pain and compensation is soon restored. I have never seen the symptoms of angina pectoris occur in a heart with broken compensation, and I thoroughly agree with Sir Clifford Allbutt when he says that the aorta is chiefly associated with these distressing symptoms. Three cases which $I$ have noticed in hospital were of a very severe type and all terminated fatally, but, strange to say, none of the cases died during an attack or even near an attack of angina pectoris. Two of them occurred regularly after an excess of food, the third one developed angina occasionally after smoking sirong tobacco. I kept very careful notes of the clinical course and also of the necropsies of these three patients. In the first. case the heart was enlarged, weighing $12 \frac{1}{2}$ ounces, there was hypertrophy of the left ventricle with thickening of the aortic valves, and marked atheroma of the aorta through its whole extent. None of the chambers of the heart were distended, and the left side of the heart was quite empty. In Case No. 2 the heart was slightly enlarged with hypertrophy of the left ventricle and some aortic incompetence. In this case also the aorta showed atheroma. The heart itself was in a state of firm contraction. The coronary arteries in both these cases were patent and there was very little evidence of arterial degeneration. In the third case, where the attacks were induced by smoking, the heart was to all appearances quite healthy and the man died from advanced kidney disease.

To look at the other side of the picture, I have made necropsies on some hundreds of cases of heart disease in all its forms, including aneurysm and intra-thoracio growths, and I am sure that it is the experience of all of us that it is common to see all the rarious lesions and degenerations associated with the heart without the slightest sign during life of angina pectoris, so that we cannot say that diseases of the valves of the heart or of the aorta alone are the cause of angina. There seems to be some affinity or relation between gout, especially the gouty heart, and angina pectoris, and as it is rare to see acute gout in the female so it is rare to see angina pectoris ; in fact, I have not met with a true case in the female. Then with regard to its neuralgic character, although the pain is severe and excruciating, exd tending, as Head has said, into various nervous areas, still the character of the pain cannot be said to coincide with neuralgia. The sudden onset, short duration, and rapid cessation are quite opposed to neuralgia and yet would correspond with spasm or cramp of the heart muscle. It is well known that gouty people are very prone to attacks of cramp, and it is quite feasible to suppose that the heart muscle may be subject to cramp also, and that the administration of any drug which produces dilatation of the arteries may also relieve muscular spasm.

Another point to consider is the extraordinary feeling which the patient suffers of impending death. In many cases; however, this feeling is due to fright caused by the intense pain. Patients have told me that the very thought of the possibility of an attack would produce the same kind of fear, and such patients live in constant dread of an attack. have recently had under my care a gentleman of highly gouty tendencies who has been subject to attacks of angina pectoris for over 25 years. He had aortic disease following rheumatism, and although the pain towards the end of his life was just as acute, yet he told me that the fear and dread 